\title{
Fault Examination of a 400kV Switchyard of 500MW Thermal Power Plant
}

\author{
Sudhakar Uppala, S.V.S Phani Kumar.Ch
}

\begin{abstract}
The present paper deals with Load flow and stability analysis of thermal power plant. In the thermal power plant switchyards plays vital role in various control, security and monitoring features that enable robust routing of power from generators to loads through a complex network of transmission lines. Analysis of such switchyard is the key and most important task for planning of the Generation plant. In the past there have been many widespread blackouts in interconnected power systems, so it is essential to assure that power system must operate more stablely and reliably. In this present discussion, the adopted system of 500MW Thermal power plant comprises a generator bus connected to 6 load buses and 1 utility bus interconnected with $400 k$ V transmission lines. Power flow studies and fault analysis are simulated in Power World simulator environment. These studies include the operating points when faults occurred in the system for the system reliability, line outages and its impact on other transmission lines such as incoming or outgoing lines and also on bus sections. Prior to planning and construction of substation, these studies help to calculate indices that reflect the reliability performance of the system. These analyses give the detail overview for future growth of power generation and subsequent extension of switchyard.
\end{abstract}

Keywords : Fault Analysis of 400kV switchyard of thermal power plant, Newton-Raphson (NR) method, Power Flow Analysis.

\section{INTRODUCTION}

The intention of an electrical power system is to generate power and supply it to consumers more reliably. The most hazards to the power system are the short circuit currents. A fault is defined as the flow of a huge current through an improper path that could cause huge damage to the equipment that leads to power outage, personal injury or death. Power flow analysis in the power system is the steady state solution of the power system network. The state at which a power system is before a fault occurs is known as steady state of the power system. In this paper, the power system is modeled by an electric network using power world simulator and solved for the steady state powers and voltages at various buses. Power flow analysis is called the backbone of power system analysis. Analysis of Power system faults is one of the basic problems in power system engineering. The result of power system fault analysis is used to determine the type of the protection system to be installed in the system, so as to ensure continuity of supply even when there is a fault in the system.

Revised Manuscript Received on September 22, 2019

* Correspondence Author

Sudhakar Uppala, PG Scholar, VR Siddhartha Engineering College, Vijayawada-520007, India

S.V.S Phani Kumar.Ch, Assistant Professor, VR Siddhartha Engineering College, Vijayawada-520007, India
Therefore, the evaluation of fault currents in a power system is significant because the protection devices that will be installed in the system depend on the fault current values. Faults can be grouped into symmetrical and asymmetrical faults. Faults could occur when a phase establishes a connection to another phase or earth, deterioration of lightning, wind damage, trees falling across lines, etc. Though the symmetrical faults are rare but generally lead to most severe fault current flow. The symmetrical fault analysis must be carried out to know the fault current levels to set the Circuit Breaker limits. Fault studies involve determining the voltages and currents during fault conditions so that protective devices can be selected as to minimize the harmful effect in the power system. Most of the power transmission lines of high voltage exist in India is $400 \mathrm{kV}$ transmission. Therefore fault analysis is important for $400 \mathrm{kV}$ transmission system to the power industries.

\section{PROBLEM FORMULATION}

The fault analysis of existing 500MW generator connected to $400 \mathrm{kV}$ transmission system is important for the evaluation of transmission line limits \& switchyard capacity for the future enhancement of the system. This analysis includes maximum capability of the fault currents, voltages, tie line powers and complete analysis of existing system for future load \& generation enhancement for faultless power transmission. This paper presents complete fault analysis of $500 \mathrm{MW}$ power plant and existing transmission line limits.

\subsection{Fault Studies}

Fault studies involve finding the distribution of voltages and currents throughout the power system during fault conditions so that protective devices can be configured to detect and isolate the faulty portion of the system so as to minimize the harmful effects of contingencies. Power system faults may be categorized as four types, they are:

1. SLG Fault

2. L-L Fault

3. L-L-G Fault

4. Balanced Three Phase Fault

The first three types constitutes severe unbalanced operating conditions which involves only one or two phases hence referred to as unsymmetrical faults. In the fourth type, a fault involving all the three phases therefore referred to as symmetrical (balanced) fault. The fault analysis is carried out at both buses and in-line faults. At the in line faults the fault parameters are calculated at different distances from the bus. In this paper PowerWorld simulator is used for both load flow studies and fault analysis. 


\section{POWERWORLD SIMULATOR}

PowerWorld Simulator is a power system simulation package designed from simulating the electrical power system engineering analysis. This GUI is self-explanatory and can be used to explain power system operations to lay men. In the present paper the simulation results are simulated in "Version 19 Educational licensed version". In this simulator the load flow can be done for about 100,000 buses. Transmission lines can be switched in/out from service, new transmission lines or generators can be added during the run time, and the instantaneous load flows can be observed.

Steps involved in the fault analysis study in power world simulator:

1. Implement a "single line diagram" of the complete network along with ratings, voltage and other parameters of each element of the network.

2. Determination of pre-fault conditions of simulated model using NR method.

3. Evaluation of fault current and voltage magnitudes with angles for $400 \mathrm{kV}$ switchyard by imposing three phase balanced fault on different buses.

4. Evaluation of fault voltage and current magnitudes with angles for $400 \mathrm{kV}$ switchyard when asymmetrical fault occurs on different buses of the system.

5. Evaluation of fault analysis when in-line faults occur in the system.

6. Study of behavior of power system according to step 3, 4 and 5.

\section{RESEMBLED 500MW THERMAL POWER PLANT DATA}

The present resembled system presented in the paper comprising of a 500MW Thermal generator connected to 6 load buses and 1 utility bus interconnected with $400 \mathrm{kV}$ transmission lines. The generation and load data of the System are shown in below Table 1.

Table 1. Generation and load data

\begin{tabular}{|c|c|c|c|c|c|}
\hline \multirow{2}{*}{$\begin{array}{c}\text { Bus } \\
\text { no. }\end{array}$} & \multirow{2}{*}{$\begin{array}{c}\text { Nominal } \\
\text { voltage } \\
(\mathrm{kV})\end{array}$} & \multicolumn{2}{|c|}{ Generation } & \multicolumn{2}{|c|}{ Load } \\
\cline { 3 - 6 } & 400 & - & - & 64 & 70 \\
\hline 1 & 400 & - & - & 74 & 64 \\
\hline 3 & 400 & Mvar & MW & Mvar \\
\hline 4 & 400 & - & - & 104 & 84 \\
\hline 5 & 400 & - & - & 112 & 78 \\
\hline 6 & 400 & - & - & 78 & 28 \\
\hline 7 & 400 & 100 & 150 & - & - \\
\hline 10 & 21.5 & 500 & 120 & - & - \\
\hline 11 & 400 & - & - & 8 & 7.5 \\
\hline
\end{tabular}

Resistance(R), Reactance(X) and Susceptance (B/2) values are evaluated as per the conductor standards specified for Aluminum Conductor Steel Reinforced conductor for transmission line. In the present system the existing conductor is a double Moose conductor and accordingly data for some selected conductors for transmission lines is furnished in Table 2.
Table 2. Values for Resistance(R), Reactance(X) and Susceptance (B/2)

\begin{tabular}{cccc}
\hline Bus-Bus & $\begin{array}{c}\mathrm{R} \\
\text { (p.u) }\end{array}$ & $\begin{array}{c}\mathrm{X} \\
\text { (p.u) }\end{array}$ & $\begin{array}{c}\mathrm{B} / 2 \\
\text { (p.u) }\end{array}$ \\
\hline $1-2$ & 0.0043 & 0.06 & 0.05 \\
$7-8$ & 0.0006 & 0.24 & 0.05 \\
$2-6$ & 0.0115 & 0.332 & 0.015 \\
$8-5$ & 0.0018 & 0.12 & 0.03 \\
\hline
\end{tabular}

\section{SIMULATION AND RESULTS}

The below Fig.1 contains that the layout of $400 \mathrm{kV}$ switchyard implemented in power world simulator which consists of 1 generator bus, 6 load buses and 1 utility bus interconnected with $400 \mathrm{kV}$ transmission lines.

Load flows are evaluated for the system mentioned above by the NR method. The main information obtained from this study is the magnitude and phase angle of the voltage at each bus, the active and reactive powers that flow in each line that are shown in Table 3.

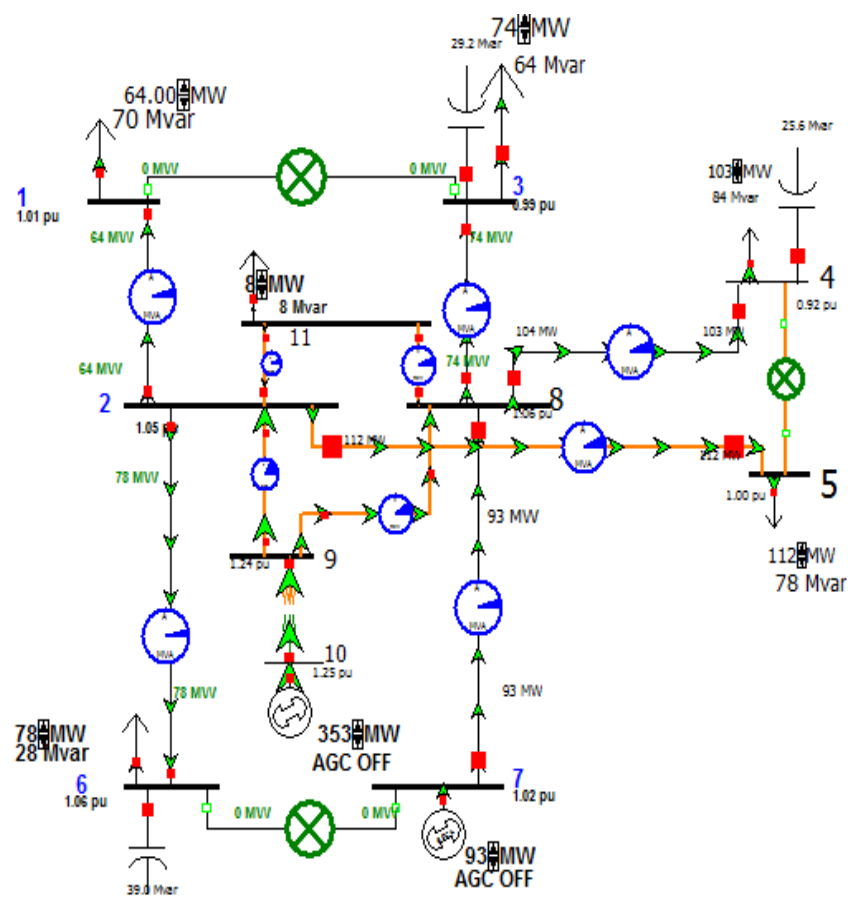

Figure 1: 400kV Switchyard layout of 500MW Power plant in power world simulator

\subsection{Results and Discussion}

When a three phase balanced fault occurs in the transmission station, the voltage at faulted point is reduced to zero and it is observed the current raised to 4-7 times of the line rated. Comparing the voltage magnitudes in Table 4 , it is observed that voltage magnitudes at faulty buses are lowered to zero when fault occurs at bus 3 and 11 . From Table $5 \& 6$, it is observed that the current magnitudes at generator buses are extremely high. 
Table 3. Bus Records Using Power World Simulator

\begin{tabular}{|c|c|c|c|c|c|c|}
\hline $\begin{array}{l}\text { Bus } \\
\text { no. }\end{array}$ & $\begin{array}{c}\text { Nom } \\
\mathrm{kV}\end{array}$ & PU Volt & $\begin{array}{c}\text { Voltage } \\
(\mathrm{kV})\end{array}$ & $\begin{array}{l}\text { Angle } \\
\text { (Deg) }\end{array}$ & $\begin{array}{l}\text { Gen } \\
\text { MW }\end{array}$ & $\begin{array}{l}\text { Gen } \\
\text { Mvar }\end{array}$ \\
\hline 1 & 400 & $\begin{array}{c}1.0075 \\
4\end{array}$ & $\begin{array}{c}403.01 \\
8\end{array}$ & 10.98 & & \\
\hline 2 & 400 & $\begin{array}{c}1.0500 \\
7\end{array}$ & $\begin{array}{c}420.02 \\
9\end{array}$ & 12.96 & & \\
\hline 3 & 400 & $\begin{array}{c}0.9869 \\
6 \\
\end{array}$ & $\begin{array}{c}394.78 \\
4 \\
\end{array}$ & 12.10 & & \\
\hline 4 & 400 & $\begin{array}{c}0.9242 \\
1\end{array}$ & $\begin{array}{c}369.68 \\
3\end{array}$ & 8.60 & & \\
\hline 5 & 400 & $\begin{array}{c}1.0008 \\
2\end{array}$ & $\begin{array}{c}400.32 \\
8\end{array}$ & 9.37 & & \\
\hline 6 & 400 & $\begin{array}{c}1.0554 \\
8\end{array}$ & $\begin{array}{c}422.19 \\
1\end{array}$ & 1.52 & & \\
\hline 7 & 400 & $\begin{array}{c}1.0240 \\
0\end{array}$ & $\begin{array}{c}409.60 \\
0\end{array}$ & 31.22 & $\begin{array}{c}93.0 \\
2\end{array}$ & -112.2 \\
\hline 8 & 400 & $\begin{array}{c}1.0597 \\
1\end{array}$ & $\begin{array}{c}423.88 \\
2\end{array}$ & 19.31 & & \\
\hline 9 & 400 & $\begin{array}{c}1.0719 \\
1\end{array}$ & $\begin{array}{c}428.76 \\
4\end{array}$ & 25.10 & & \\
\hline 10 & 21.5 & $\begin{array}{c}1.0800 \\
0\end{array}$ & 23.22 & 25.43 & $\begin{array}{c}352 . \\
7\end{array}$ & $\begin{array}{c}405.2 \\
6\end{array}$ \\
\hline 11 & 400 & $\begin{array}{c}1.0506 \\
6\end{array}$ & $\begin{array}{c}420.26 \\
5\end{array}$ & 15.70 & & \\
\hline
\end{tabular}

Table 4. Voltage magnitude and angles of all buses when three phase balanced (symmetrical) fault occurs on buses $3 \&$ 11

\begin{tabular}{|c|c|c|c|c|}
\hline \multirow{2}{*}{ Bus } & \multicolumn{2}{|c|}{ Fault on bus 3 } & \multicolumn{2}{c|}{ Fault on bus 11 } \\
\cline { 2 - 5 } & $\begin{array}{c}\text { Magnitude } \\
\text { (p.u) }\end{array}$ & $\begin{array}{c}\text { Angle } \\
\text { (ang) }\end{array}$ & $\begin{array}{c}\text { Magnitude } \\
\text { (p.u) }\end{array}$ & $\begin{array}{c}\text { Angle } \\
\text { (ang) }\end{array}$ \\
\hline 1 & 0.68556 & 58.68 & 0.41684 & 66.50 \\
\hline 2 & 0.71449 & 60.66 & 0.43443 & 68.48 \\
\hline 3 & 0.00000 & 00.00 & 0.45175 & 68.37 \\
\hline 4 & 0.48478 & 59.82 & 0.42303 & 64.86 \\
\hline 5 & 0.68098 & 57.07 & 0.41405 & 64.89 \\
\hline 6 & 0.71817 & 58.22 & 0.43667 & 66.04 \\
\hline 7 & 0.67381 & 82.78 & 0.62499 & 86.99 \\
\hline 8 & 0.55584 & 70.53 & 0.48504 & 75.57 \\
\hline 9 & 0.88540 & 71.96 & 0.72906 & 77.82 \\
\hline 10 & 0.89594 & 72.19 & 0.74029 & 77.99 \\
\hline 11 & 0.63128 & 64.48 & 0.00000 & 00.00 \\
\hline
\end{tabular}

Table 5. Current magnitudes and angles of generator buses when three phase balanced fault imposed on bus 3

\begin{tabular}{ccc}
\hline Bus & $\begin{array}{c}\text { Current } \\
\text { magnitude (p.u) }\end{array}$ & $\begin{array}{c}\text { Angle } \\
\text { (deg) }\end{array}$ \\
\hline 7 & 0.72077 & -82.31 \\
10 & 4.44745 & -119.37 \\
\hline
\end{tabular}

Table 6. Current magnitudes and angles of generator buses when three phase balanced fault imposed on bus 11

\begin{tabular}{ccc}
\hline Bus & $\begin{array}{c}\text { Current magnitude } \\
\text { (p.u) }\end{array}$ & $\begin{array}{c}\text { Angle } \\
\text { (deg) }\end{array}$ \\
\hline 7 & 0.72731 & -87.69 \\
10 & 4.57664 & -120.89 \\
\hline
\end{tabular}

These predetermined simulation results in the particular case give the information of selection of rating of the Circuit Breaker and it settings. This analysis will be important for

planning of future expansion. Voltage magnitude and angles of all buses when SLG fault occurs on bus 1is shown in Table 7.

Table 7. SLG Fault on bus 1

\begin{tabular}{|c|c|c|c|c|c|c|}
\hline \multirow{2}{*}{ Bus } & \multicolumn{3}{|c|}{ Phase Voltage (p.u) } & \multicolumn{3}{|c|}{ Phase Angle (deg) } \\
\hline & A & $\mathrm{B}$ & $\mathrm{C}$ & A & $\mathrm{B}$ & $\mathrm{C}$ \\
\hline \multirow{2}{*}{1} & 0.0000 & 1.7066 & 1.6599 & -88.4 & 133. & 71.0 \\
\hline & 0 & 4 & 9 & 1 & 5 & 8 \\
\hline \multirow{2}{*}{2} & 0.0830 & 1.7144 & 1.7011 & -52.4 & 135. & 71.1 \\
\hline & 4 & 6 & 1 & 4 & 4 & 4 \\
\hline \multirow{2}{*}{3} & 0.1619 & 1.5644 & 1.5377 & -72.3 & 136. & 69.4 \\
\hline & 7 & 6 & 3 & 4 & 2 & 1 \\
\hline \multirow{2}{*}{4} & 0.1076 & 1.5339 & 1.4559 & -100. & 133. & 68.6 \\
\hline & 8 & 4 & 9 & 5 & 3 & 2 \\
\hline \multirow{2}{*}{5} & 0.0360 & 1.7050 & 1.6317 & -126. & 132. & 70.1 \\
\hline & 8 & 6 & 2 & 0 & 7 & 7 \\
\hline \multirow{2}{*}{6} & 0.0780 & 1.7433 & 1.6874 & -83.2 & 134. & 69.8 \\
\hline & 7 & 9 & 4 & 6 & 2 & 2 \\
\hline \multirow{2}{*}{7} & 0.5614 & 1.2393 & 1.4261 & -40.2 & 158. & 75.1 \\
\hline & 9 & 5 & 1 & 2 & 2 & 5 \\
\hline \multirow{2}{*}{8} & 0.2719 & 1.5639 & 1.6499 & -44.9 & 141. & 72.3 \\
\hline & 8 & 8 & 9 & 3 & 9 & 1 \\
\hline \multirow{2}{*}{9} & 0.4271 & 1.7221 & 1.9225 & -34.1 & 146. & 74.7 \\
\hline & 7 & 2 & 6 & 6 & 8 & 3 \\
\hline \multirow{2}{*}{10} & 1.2299 & 1.2590 & 1.2308 & -63.0 & 176. & 55.3 \\
\hline & 9 & 3 & 7 & 6 & 2 & 9 \\
\hline \multirow{2}{*}{11} & 0.1599 & 1.6492 & 1.6808 & -46.5 & 137. & 71.7 \\
\hline & 3 & 7 & 5 & 9 & 9 & 0 \\
\hline
\end{tabular}

Table 8. Current magnitudes and angles at generator buses when SLG fault imposed on bus 1

\begin{tabular}{ccc}
\hline Bus & $\begin{array}{c}\text { Current magnitude } \\
(\text { p.u })\end{array}$ & $\begin{array}{c}\text { Angle } \\
(\mathrm{deg})\end{array}$ \\
\hline 7 & 0.82369 & -86.42 \\
10 & 4.29256 & -114.04 \\
\hline
\end{tabular}

Table 9.SLG Fault on bus 5

\begin{tabular}{|c|c|c|c|c|c|c|}
\hline \multirow{2}{*}{$\mathrm{Bu}$} & \multicolumn{3}{|c|}{ Phase Voltage (p.u) } & \multicolumn{3}{c|}{ Phase Angle (deg) } \\
\cline { 2 - 7 } $\mathrm{S}$ & $\mathrm{A}$ & $\mathrm{B}$ & $\mathrm{C}$ & $\mathrm{A}$ & $\mathrm{B}$ & $\mathrm{C}$ \\
\hline \multirow{2}{*}{1} & 0.0467 & 1.6812 & 1.6603 & -43.0 & 133.0 & 70.0 \\
& 0 & 1 & 9 & 5 & 4 & 8 \\
\hline \multirow{2}{*}{2} & 0.1028 & 1.6981 & 1.7104 & -40.7 & 134.8 & 70.3 \\
& 4 & 8 & 8 & 4 & 8 & 8 \\
\hline \multirow{2}{*}{3} & 0.1711 & 1.5499 & 1.5465 & -65.1 & 135.7 & 68.6 \\
& 8 & 2 & 5 & 8 & 1 & 9 \\
\hline \multirow{2}{*}{4} & 0.1068 & 1.5201 & 1.4651 & -88.5 & 132.6 & 67.8 \\
& 7 & 8 & 0 & 0 & 8 & 5 \\
\hline \multirow{2}{*}{5} & 0.0000 & 1.6993 & 1.6505 & -17.2 & 131.9 & 69.6 \\
& 0 & 2 & 3 & 6 & 1 & 0 \\
\hline \multirow{2}{*}{6} & 0.0869 & 1.7274 & 1.6974 & -65.1 & 133.5 & 69.0 \\
& 4 & 7 & 1 & 8 & 8 & 6 \\
\hline \multirow{2}{*}{7} & 0.5731 & 1.2275 & 1.4305 & -39.3 & 157.9 & 74.6 \\
& 7 & 1 & 9 & 3 & 8 & 5 \\
\hline \multirow{2}{*}{8} & 0.2892 & 1.5482 & 1.6577 & -41.8 & 141.3 & 71.6 \\
& 3 & 1 & 0 & 9 & 8 & 3 \\
\hline \multirow{2}{*}{9} & 0.4487 & 1.7037 & 1.9299 & -32.4 & 146.3 & 74.0 \\
& 0 & 3 & 4 & 7 & 8 & 8 \\
\hline
\end{tabular}


Fault Examination of a 400kV Switchyard of 500MW Thermal Power Plant

\begin{tabular}{|c|c|c|c|c|c|c|}
\hline 10 & 1.2320 & 1.2598 & 1.2310 & -63.0 & 176.1 & 55.4 \\
& 4 & 1 & 9 & 4 & 6 & 4 \\
\hline \multirow{2}{*}{11} & 0.1790 & 1.6331 & 1.6895 & -40.9 & 137.3 & 70.9 \\
& 9 & 0 & 0 & 4 & 7 & 7 \\
\hline
\end{tabular}

\begin{tabular}{||c|c|c|c|c|c|c|}
\hline 4 & $\begin{array}{c}1.352 \\
3\end{array}$ & $\begin{array}{c}0.351 \\
1\end{array}$ & 0.4150 & -80.08 & -144.46 & 40.02 \\
\hline 5 & $\begin{array}{c}1.498 \\
3\end{array}$ & $\begin{array}{c}0.020 \\
8\end{array}$ & 0.0208 & -79.52 & -28.92 & -28.89 \\
\hline 6 & $\begin{array}{c}1.549 \\
2\end{array}$ & $\begin{array}{c}0.103 \\
7\end{array}$ & 0.1366 & -78.77 & -139.34 & 52.78 \\
\hline 7 & $\begin{array}{c}1.279 \\
9\end{array}$ & $\begin{array}{c}0.586 \\
7\end{array}$ & 0.6540 & -62.35 & -148.49 & 82.81 \\
\hline 8 & $\begin{array}{c}1.480 \\
5\end{array}$ & $\begin{array}{c}0.456 \\
2\end{array}$ & 0.4530 & -72.55 & -146.44 & 63.91 \\
\hline 9 & $\begin{array}{c}1.693 \\
6\end{array}$ & $\begin{array}{c}0.581 \\
7\end{array}$ & 0.5354 & -68.25 & -147.41 & 74.02 \\
\hline 10 & $\begin{array}{c}1.244 \\
6\end{array}$ & $\begin{array}{c}0.611 \\
0\end{array}$ & 0.9841 & -64.16 & 167.01 & 86.92 \\
\hline 11 & $\begin{array}{c}1.514 \\
7\end{array}$ & $\begin{array}{c}0.288 \\
2\end{array}$ & 0.2821 & -75.25 & -144.11 & 61.33 \\
\hline $\begin{array}{c}\text { Faul } \\
\mathrm{t} \\
\text { Path }\end{array}$ & $\begin{array}{c}1.521 \\
6\end{array}$ & $\begin{array}{c}0.000 \\
0\end{array}$ & 0.0000 & -78.31 & 21.14 & 22.05 \\
\hline
\end{tabular}

Table 12. Current magnitudes and angles of generator

Table 11. Voltage magnitudes and angles of all buses when In-line fault (LLG fault) occurs at $50 \%$ of the transmission line between the buses $2 \& 5$

\begin{tabular}{|c|c|c|c|c|c|c|}
\hline \multirow{2}{*}{ Bus } & \multicolumn{3}{|c|}{ Phase Voltage (p.u) } & \multicolumn{3}{c|}{ Phase Angle (deg) } \\
\cline { 2 - 7 } & A & B & C & A & B & C \\
\hline 1 & $\begin{array}{c}1.501 \\
8\end{array}$ & $\begin{array}{c}0.115 \\
0\end{array}$ & 0.1133 & -78.47 & -129.87 & 45.85 \\
\hline 2 & $\begin{array}{c}1.541 \\
8\end{array}$ & $\begin{array}{c}0.122 \\
3\end{array}$ & 0.1206 & -77.13 & -141.62 & 61.77 \\
\hline 3 & $\begin{array}{c}1.415 \\
0\end{array}$ & $\begin{array}{c}0.388 \\
8\end{array}$ & 0.4359 & -77.69 & -146.59 & 48.66 \\
\hline
\end{tabular}

buses when In-line fault (LLG fault) occurs at $50 \%$ of the transmission line between the buses $2 \& 5$

\begin{tabular}{ccc}
\hline Bus & $\begin{array}{c}\text { Current } \\
\text { magnitude (p.u) }\end{array}$ & $\begin{array}{c}\text { Angle } \\
(\mathrm{deg})\end{array}$ \\
\hline 7 & 1.05285 & -38.56 \\
10 & 4.29343 & -113.63 \\
\hline
\end{tabular}

Based on the simulation results, considering both symmetrical and unsymmetrical faults the selection of ratings for switchgear equipment i.e., circuit breakers in power transmission stations is furnished in Table 13.

Table 13. Circuit breaker details for $400 \mathrm{kV}$ switchyard

\begin{tabular}{cccccc}
\hline Feeder number & $\begin{array}{c}\text { Rated voltage } \\
(\mathrm{kV})\end{array}$ & $\begin{array}{c}\text { Breaking current } \\
(\mathrm{kA})\end{array}$ & $\begin{array}{c}\text { Making current } \\
(\mathrm{kA} \text { peak })\end{array}$ & Rated frequency(Hz) & STC(kA/1sec) \\
\hline 1 & 420 & 40 & 100 & 50 & $40 \mathrm{kA}$ \\
\hline
\end{tabular}

\section{CONCLUSION}

In this paper load flow studies and fault analyses are performed for the $400 \mathrm{kV}$ switchyard of the 500MW power plant, which is of great importance in the planning and design for future load improvement and power system generation, as well as in determining the best functioning of existing systems. The magnitudes and phase angles of the voltages at each bus and the real \& reactive power flows in each line are obtained. For future studies if there is any requirement of generation upgradation and to add any additional generators to the existing switchyard, these studies may be included. This study helps the system operator in enhancement of transmission line, breaker and relay setting accordingly in order to integrate and for smooth operation of existing $400 \mathrm{kV}$ switchyard. The Power World simulator can also simulate and will give a scope to analyze the data to obtain the power flow analysis and also it is simple to do contingency analysis for the system to find the line limits feasibility for un-interruption power flow to the consumer. These studies will help for planning and construction of power transmission system.

\section{REFERENCES}

1. T. Guler, G. Gross, M. Liu, "Generalized Line Outage Distribution Factors", Power Systems, IEEE Transactions Vol.22, Issue 2, May 2001.

2. L. Czumbil, S.F. Braicu, D.D. Micu, D. Stet, A. Ceclan, "Analysis of Load Flow and Short-Circuit Issues in a Retrofitted 110/20 kV Romanian Substation" 14th International Conference on Engineering of Modern Electric Systems (EMES) 2017.

3. Jegan Diravianath S, Ajith A, Dharaniram T S, Gokulnath M, And Balaji T. "Monitoring and Control of Component Transfer and Packing through Conveyors Using PLC, SCADA and Mobile Application." International Journal of Communication and Computer Technologies 7.Supplement 1 (2019), 35-37. Print. doi:10.31838/ijccts/07.SP01.09

4. Alejandro Garces, "A Linear Three-Phase Load Flow for Power Distribution Systems", IEEE Trans. on Power System, Vol. 31, No.1, January 2016.

5. Babu, T. Vandana, T. Satyanarayana Murthy, and B. Sivaiah. "Detecting unusual customer consumption profiles in power distribution systems-APSPDCL." 2013 IEEE International Conference on Computational Intelligence and Computing Research. IEEE, 2013.

6. PowerWorld simulator User's-Guide.

7. https://www.powerworld.com/Simulator16_Help_Printed.pdf

8. J. Jangra, S. Vadhera, "Load Flow Analysis for three phase unbalanced distribution feeders using Matlab", 2nd International Conference for Convergence in Technology, NIT Kurukshetra, 2017 